\title{
Study in the Virtual Class: Doings of Feminist Pedagogy and the Covid-r9 Crisis
}

Renata Šribar, Centre FemA - Institute of Transformation Studies and Agency, Ljubljana, Slovenia

\section{Introduction}

N any of us reflecting on our lecturing practices wish to deconstruct the ex-cathedra teaching, its symbolic dimensions and multilayered effect on our students. The presented inquiry reflects on contemporary and pandemic-related feminist pedagogy along with an explication of the author's own teaching practice. It is this applied side of my reflection that allows for switching over to the narrative "I".

The auto-ethnographic references I am using were obtained during precarious work engagement in tertiary-level education. In the study years 2019/20 and 2020/2I we, meaning my students and myself, have been and still are co-construing the studying process at the Faculty of Education at the University of Ljubljana in the subjects Gender specific socialisation, and Ethics and morals in science, and also at the Faculty of Social Work in the subject Gender and Violence in the Erasmus Programme.

After 5 years of teaching at Slovenia's public universities, I was certain that some intuitive pedagogic approaches are worth practising, and that this moment is the psychic milestone, indicating the personal need to enhance the two-way transfer of knowledge with new pedagogical inputs. The switch to digitalised classes, which was initially unwanted, has induced a step-by-step transition to the more structured integration of feminist pedagogy. Its elaboration under the special academic conditions of the anti-Covid-rg regimes has not only been my task but, as I was later informed, the effort of many feminist lecturers. Indicators of such endeavours are the surprisingly numerous blogs and expert Internet sources 
dealing with feminist pedagogy and digitalisation of the class during the Covid-19 crisis.

The first part of the discussion consists of my own modelling of feminist teaching, a summary of the characteristics of feminist and critical pedagogy, and the use of certain related theses. In the second part, a selection of feminist pedagogic Internet blogs and expert inputs related to virtual classes during the Covid-I9 crisis is integrated. Accompanying auto-ethnographic notes deliver my reflections on the personal spontaneous and informed approaches in virtual classes, which correspond to the feminist pedagogy guidelines disseminated via the Internet. The final part aims at an innovative subjective contribution to the contemporary feminist interventions in the virtualised studying processes and modes.

\section{Feminist Pedagogy, "Situated Knowledges”, Transformative Power}

After my initial teaching efforts at transposing all-the knowledge-youhave followed the transition to a more relaxed praxis. Over the next few years, I was developing certain unconventional approaches.

The traits of such seemingly spontaneous subjective realisations of the curriculum are shortlisted and sometimes accompanied by the respective objectives:

- addressing the students by feminine grammatical gender forms to practically demonstrate gender discrimination in language to the men present;

- $\quad$ addressing the students by their first names, and inviting them to omit use of the title professor while addressing me; I do not use any other formal language forms of addressing, which are formal, although I stick to politeness and kindness. The students may use the same mode while addressing me. Such interpersonal closeness is in my case much more realisable with the Erasmus students;

- unannounced transformations of the formal teaching plan to show how the actual socio-political or other socio-cultural actual phenomena and situations relate to a topic related to the study subject;

- $\quad$ reorganising a lecture room (if possible) so as to substantially subvert the unequal positions in the two-way transfer of knowledge. If not possible, I often take a seat among the students to make it easier for them to talk and share their thoughts;

- $\quad$ reporting my own experiences which relate to the exposed theses or topics; the aim is to practically illustrate that there is no real theory/ praxis gap. I do not apply pressure to them to expose themselves in 
the same manner. Besides, I try to interpret my experiences sincerely and in a dignified manner;

- suggesting that the students define their location at the intersection of social divisions, and survey their pre-existing knowledge of the research subject in the introductory part of the seminar or exam essay; besides, students are inspired to articulate a strategic plan to improve a social issue ("policy paper") in the conclusion of the essay;

- expressing an emotional charge when I feel it while theoretically confronting systemic and structural discrimination and exclusion; I typically explicitly relate such a display of emotions to the need for active citizenship;

- conceiving grades as a structural must, and trying to put more effort than usual into the descriptive evaluation of the students' work. When possible, I discuss together with the students their aural and written deliveries according to the pre-formulated criteria, and decide on each grade; and

- $\quad$ using certain themes with every study subject to formulate the basic epistemic framework needed; such thematic involvement is in line with the feminist knowledge and usable in every discipline, at least when studying humanities and/or social sciences.

Certain epistemic issues brought to light by feminist lenses restructure our perception of teaching and research. The following conceptualisations are the crucial theoretical tools I use to expose in all my lecture courses.

- "Partial objectivity", "situated knowledges", subject/object relation, and "positioning" (Haraway, 1999, pp. 298-309; Vendramin, 2009, pp. 64-66) in the study and research processes; these concepts are in opposition to thinking "traditional" objectivity and universal truth as epistemic facts.

- The knowledge-ignorance relationship, and the taxonomy of ignorance (Tuana \& Sullivan, 2006; Sribar, 2015, p. 50) and by analysing ignorance as a produced socio-cultural and political phenomenon of knowledge (science included) become transparent. The deconstruction of knowledge and ignorance implementing governmentality, capital, and gender perspective.

- The deconstruction of unjust socio-cultural hierarchies, academic institutions included; I consider hierarchies/axes of social divisions to be social constructions, which are the main structural and ideological/mental obstacles to the possibility of thinking human equality and equity. 
- The nature of experiences, which connect the known and the lived. By such implicit meaning of experiences, the dialectics of interpreting realities and experiencing them is revealed.

- The power relations and the three-level approach to research issues (systemic, structural, individual). All socio-cultural, political and psycho-social realities may be grasped by a consideration of different levels on which meanings, institutions and individual life options are construed. During lectures, I give examples of the patriarchal societies, their structures, and individual interiorisation and incorporation of gendered myths, social proscriptions, and cultural norms.

- The intersectional approach is introduced to enhance understanding and studying social inequalities. The complex discrimination which I present using mundane cases brings the normalised discriminating practices closer to the students, our own discriminatory practices, too. Besides, I promote the intersectional analysis as a self-positioning tool for the students while doing seminar or exam-related research.

- The deconstruction of dichotomies in mainstream thinking has a mind-opening effect in students. The regularly presented and analysed categorical pairs I refer to besides knowledge/ignorance are: nature/culture, global/local, private/public, mind/emotions, sex/ gender, representation (in the meaning of mimicking a reality)/ construction.

What seemed to be intuitive intervention in the curriculum and the phalogocentric pedagogic canon must be considered from the perspective of situated knowledges. The spontaneity in lecturing I have been practising has been embedded in the pre-existing feminist position and adopted knowledges. The feminism I have been subjectivated into was formed by individually selected readings, conveying the theses and arguments of feminist theories, and critical sociological and philosophical studies. The feminist scholarship was thematically and epistemologically accompanied by performing active citizenship. E.g. when studying and deconstructing pornography and the pornographisation of culture I was involved in civil society's endeavours to co-regulate porn. Consequentially, my self-positioning in academia and research has developed transformative features, I have learned to study, inquire, and teach with the defined and publicly articulated aims to transform the realities in the class and in my professional vicinity.

According to their feedback, feminist knowledge and interpretations of my own experiences have been stimulating the students' thinking. 
I have been inspired to look for theoretical references for my own praxis in feminist and critical pedagogy ${ }^{\mathrm{I}}$ and thus provide a firm theoretical sub-disciplinary basis for elaborating the existing teaching attitude and habits in class. Although my teaching subjects are of the SSH disciplines, not all teaching objectives and students' interests are restricted according to the MINT/SSH gap.

In his authorial introduction to the monograph The word to young people: Dialogue with the generation of active nibilism, Umberto Galimberti (2018) claims that apart from the study objectives the pedagogic stress should be put on the personal development and socio-cultural considerations of the students. An elaboration of skills and knowledges is needed for the inquiry into the contemporary socio-cultural conditioning of living. The university is determined by both socio-cultural and political conditions. Consequently, it should be in our pedagogic interest to define the macrosystemic order, the "grey zone" of the intertwined democratic and autocratic traits of our contemporary societies. This is the totality which encourages and at the same time supresses critical, oppositional feminist pedagogy. We have to deal with the intrusion of the governmental and international macro political and economy orientation which contaminates academia with autocratisation. The sensitivity to macro-systems, and the transpositions of these systems to national and global structural phenomena, inspire the interventions in the curriculum mentioned previously.

What has happened in Slovenia is that after a right-wing party won the by-elections, "Orbanisation" started in the first quarter of 2020 . The Slovenian "democratic erosion" (Lührmann \& Staffan, 2016, para $48^{2}$ ) has in its radical phase taken a form typical of contemporary de-democratisations: manipulative strategies performed without much effort of the executors to hide them; gradually intensified pressure on the media, state institutions and the public; a concentration of executive power in the patriarchy; the subversion of accountability and other values; capital requirements over nature and the destruction of national natural resources; the breaking up of the public health and education systems; complex militarisation; the promotion of a discriminatory discourse and practices in public life and politics together with other violations of human and citizens' rights; instability of work by way of massive precariousness, existential endangerment or anxiety due to poverty, violence towards gender and

I Most of the references used here are freely available. Precarious research work does not allow expenses for articles and books to be bought, which is a problem worth thematising on some other occasion.

2 The part "In democracies: the third wave of autocratization has a legal façade". 
sexual minorities, and paramilitary groups. The academic sphere, which is considered autonomous, has evidently been tackled by these processes.

In autumn and winter 2020, the degradation of democracy was nationally accelerated by the government's abuse of the anti-Covid-ig efforts with an autocratic discourse and measures directly and unnecessarily violating human rights and democratic fundaments. Public uncertainties and critiques in the media of the arguments used in support of such measures are based on the inconsistency of the measures and their insufficient effect. One of the most rigid measures is elementary school children's serious deprivation of in-situ school and free-time activities with their peers.

The governmental promotion of such anxiety and tension through the transparent production of uncertainty, ignorance and unintelligibility is reminiscent of Hannah Arendt's intellectual perception of the leading feature of governmentality in a totalitarian regime (Arendt, 1973, pp. 34-35). Paradoxically, the government's promotion of ignorance, and generally even the heyday of induced stupidity and the manipulative nature of the public discourses, is not corrupting students to any detectable extent. It seems that they are sensitised to social disadvantages because of their own poverty, primary-family problems related to substantial living uncertainties and the lack of future prospects in times of an economic and environmental crisis. During certain lectures at the Faculty of Social Work, most students could identify themselves as poor with regard to living conditions while we were discussing poverty. It was like the unexpected and the numerous coming out of the closet. When working on a methodology to ascertain how the discussion in a focus group should be carried out, two 20-year-old women students out of seven talked of tiredness and exhaustion. Their mothers had been unable to sustain their usual functions, and from time to time they had sought advice and lent completely on their daughters. Both students believed that the "daughter-mother roles are changed for periods of time, and it is tiresome to switch on and on from the daughter's role to mothering one's own mothers, and then be a daughter again." I told the two students that I was sad for them aware of the contradictory emotions, because that was the case. I tried to empower them to take a more autonomous position within their families. Before we parted company, I felt that I had given power and also received it. The feeling of gain was based on the idea that I had elaborated the skill of understanding and emotionally perceiving something psychical which has been going on between mothers and daughters forever. In the psychoanalytical framework, it is about an intimate and contradictory gender-identification process with daughters. With mothers, it is the socio-psychological framework which offers an interpretation related to the challenging 
myth of motherhood, which invites force and weakness in mothering. Immediately after that, we discussed the gendered socio-cultural conditions and the economy which are structural obstacles to the students emancipating themselves from the family traumas, equally those caused by structural problems.

The described ethnographic fragment may be provisionally formalised by the "triangulation" in feminist pedagogy with reference to knowledge production. The question of pedagogy is what or who is the central instance of the teaching and learning process. For the last three decades, the focus has been on students, as substantially presented by Carolyn M. Shrewsbury in her highly referential article "What is Feminist Pedagogy" (1993, p. 10). Schematisation revolving around the embodied focus may appear narrow in scope when the special subjective characteristics of teachers are desired, related to their "fundamental beliefs and values about teaching, learning, and knowledge-making" as stated in A Guide to Feminist Pedagogy (2015, para 2). It is one's beliefs and values that enable two-way communication and stimulate students' interests and inclinations. There are thus two instances, and in-between there is something which moves from one to the other and is in the meantime enriched. This moving entity is power which has to be shared. Yet there is no "subject" or characteristic of feminist pedagogy that is explicitly defined as mandatory and universal (Lawrence, 2016, para 6). One may conclude that there are ideas, but no strict guidelines. In her brief thematisation in Feminist Pedagogy in Issues, freely-attainable articles on the GEA - Gender and Education Association, Emilie Lawrence defines some features, "tenets", on which "there is common agreement": resisting hierarchy presupposed by the job itself by using experience as a resource, and transformative learning. The author warns us against reinforcement of the "dominant feminist narrative" by such an approach. Referring to my own praxis, I claim that the dominance of a selected perspective and discourse of a teacher deconstructed by referring to the human rights of gendered and other minorities, and to feminist ethics. I constantly try to stimulate discussions where I put the accent on the freedom to make informed personal decisions on what to think and how to live.

A fresh challenge regarding the ideas of feminist pedagogy thinkers and practitioners is detected in a novel aspect of the subject matter, accompanied by material objects. The concept of "object lesson" is inclusive of the non-conventional artefacts (Grensavitch, 2019, pp. 38-39) the teacher uses to inspire learning with exemplary materials in hand. In my appropriation of the concept, materiality is delegated to the body, it is inside and not exposed to the five senses of the others; it may be felt anyway. 
In our previously described case of the mother-daughter relationship, such an object consists of experiential value and gained knowledge, which are embodied by psycho-somatic experience in the two-way transfer going on between two equivalent instances, a teacher and a student, or a group of students. The sharing of experiences of the student/students and the teacher with the aim to articulate certain theoretic perspectives and interpretations is felt in their bodies. There are our embodied selves revolving around matrices of the unequal power relations women experience in the realm of private life. Such experiences are often reduced to a strongly felt psychologic interpretation, and in the mutual exchange of thoughts and emotions we become aware of the socio-cultural and political dimensions of the exposed interpersonal relationship.

The presented matrix of the "triangulation" of feminist pedagogy comprises the complex interrelation of student/students, the "object", a teacher, and has to be theoretically tested. "Object" is the subject matter vivified and substantialised by the force of attractive interpretations and sensations. The question is how to achieve conceptual stability of the hereby construed "triangulation". Mutual teaching/learning via the object of the embodied coupling of knowledge and experience is as follows compared to the argumentation of a liberating, democratised education. Carolyn M. Shrewsbury elaborated pedagogy in the framework of the embodied teaching/learning process by focusing on the conceptual tool for "overcoming oppressions", empowerment. The very concept of power comes from the affirmation of the Foucauldian discourse implicating embodiment. The problematic side of the idea of empowerment is that it conveys the meaning of a one-way transfer of power from the teacher to the students (Shrewsbury, 1993, p. I0). "Empowering pedagogy does not dissolve the authority or the power of the instructor. It does move from power as domination to power as creative energy" (ibid, p. II). Although the relationship of domination of the teachers over the students is interpreted as being deconstructed by "empowering pedagogy" and its reconceptualisation of power which is anyway constructive, there are two strong reasons to doubt such an interpretation. Teachers are subjected in the academic environment as are students, and they work and study in the same phalocratic and thus highly hierarchical structure. If they maintain the idea of authority and endow it with the embodied energetic message of the energy, they cannot deny the persistent unequal relationship of giving or offering and thus having and - as their counterparts - the receiving students, who do not have it, i.e. the energy and its benefits. Besides, the concept of authority is even not relativised. The fact that students have their own experiences which may inform "the instructor" when inquiring 
into a certain topic is ignored. And the students already possess adequate knowledges on subjects which are not known to the teacher. To avoid the implications of hierarchy and unethical power positioning in the form of a priori authority, the concept of empowerment has been criticised. In the field of social anthropology, Angela Cheater summoned the discussion on the problematic connotations of the concept by arguing that it might cover over the hegemonic power relations. Those who empower do not recognise the receivers' rights to define their own interests. By empowerment, they even construct them as being less able to do that (Cheater, 1999, p. 6).

The body active in the somatisation of experiences and the production of energy in the two-way teaching/learning communication cannot be devoid of its dual nature: it is described, mediated by discourse, and at the same time influenced by discourse. The pedagogic embodiments call for a collective investment in understanding the relation of the body with the symbolic and imaginary dimensions of gender-related discourse.

Just like Emilie Lawrence, some other authors consider feminist pedagogy an open structure which consists of an increasing "number of key practices" (Hassel \& Nelson, 2012). According to my comparison of expert articles and blogs on the doings of feminist pedagogy, and my own lecturing, described for the first time in the present discussion, I see identical approaches.

The similarities in personified liberating pedagogic knowledges and skills are intelligible. To practise feminist pedagogy, you need not become a scholar in the sub-field, it is sufficient to transpose feminist epistemologies to class. What might differ is the interpretation, anepistemology, and its applied imagination in response to the common denominators of feminist pedagogy. As stated, they are recognised by Emilie Lawrence, who questions the speaking dominant voices in class (2016, para 9). The consequence of the freedom in which feminism is to be applied to pedagogy are numerous options for interpreting and validating experience, and ways of using experience as a teaching/learning tool; similarly, the transformative teaching and learning is not prescribed in some universal form. This is the point of reflecting on my own pedagogic practice as logically unique: formulating a micro curriculum of the transferable feminist knowledge and skills to empower students in the field of informed active citizenship and human equality, and with the aim to let myself become powered by the students' questions, narratives and other contributions to the class community. I consider this relationship of equal importance as the reading of feminist texts; actually, it is stimulative for reading and making inquiry into new fields of feminist (trans)gender studies. The hegemonic voice of feminism in feminist pedagogy is deconstructed by the 
flexible positioning of the knowledgeable and powered subject(s). Or, as argued in the discourse of post-structural linguistics, the meanings produced in class are the product of the "floating signifier". The students are invited and stimulated to express conflicting and opposite arguments, and the studying literature is analysed critically in a comparison of contradictory theses in a text, and among texts.

\section{The Transformative Studying Praxes in the Virtual Lecturing of the Anti-Covid-rs Regime}

The transition from lecturing in the lecturing room to conducting study meetings in a Zoom personal room leads from initial discomfort to liberating effects. The experience of personal pedagogic enhancement has also been realised by the unique situation of working together with only five postgraduate students in different study courses at the Faculty, and executing a new subject Ethics and Morals in Science for the first time. In retrospect, I recognised numerous web references to feminist pedagogy, blossoming from the first Covid-ıs wave. In spite of well justified criticism of virtual studying practices, there obviously are certain stimulating moments in the evolutions of pedagogies as the sub-discipline is becoming even more pluralised. The problems and questions of feminist pedagogy have for many feminists been tackled with the new enthusiasm induced by the virtual space.

One must permanently question the possibility of establishing equality and equity in the two-way transfer of experiences, knowledges and skills. Institutionalised positions of teachers and students, socio-cultural expectations of role-related behaviour, and personal inhibitors of freeing and enriching the study are the challenges experienced. A related problem is co-construing the object of an emotionally-charged interpretation of experiences. My desire in trying to obtain the embodied, forceful interpretation of the experience is challenging despite the successes. The third issue in my use of feminist pedagogy is the constant doubt in the possibility of a transformative impact. All of these problems were highlighted from another angle defined by the virtual space. The most usual approaches to befriending students, described in the first segment of the present discussion could be sustained (e.g. addressing practice, two-way transfer of knowledge and experiences, benevolent and individualised assessment etc.). The materiality which seemed to be lost with the non-hierarchical reorganisation of the class appeared behind the screen already domesticated, and non-hierarchical as we all appear in the gallery of faces without any special position. The class has become cosier due to another factor: image. Students - a lot of them usually wearing heavy make-up 
- appear with no products on their face and in leisure clothes. Images, mine included, have lost importance and words have gained since there are fewer distractions. Zoom breakout rooms are dedicated to grouping the students into small units enabling a relaxed discussion without the teacher being present. Finally, each good-bye is performed in the vicinity of the faces, and the lack of corporeality is compensated by the friendly waving of hands. The mutual powering and transformation is moderate, verbally confirmed in larger groups by approximately one-third of the students. Their feedback consists of expressions like "I learned a lot", "this is new knowledge for me", or "I like the subject". When directly talking about the connectivity of our topics and the active citizenship for social change, my words are often reflected in the students' nods and inquiries into details of the case studies presented. My own transformations in the private and public realm which have been inspired by the students integrate an interest in feminist pedagogy, an elaborated skill of listening and feeling for the other, more patience and wisdom in reaction to the public scandals caused by government due to the government's totalitarian reactions against the protests of the non-parliamentary political left. The personality changes have not been planned or wished for. In the virtual class, I am more a moderator than a teacher, and the tenets of moderation are impacting my behaviour in and out of my professional role.

For the sake of a transparent presentation of the individual doings of feminist pedagogy in class, I am exposing the teaching and learning, i.e. the study experiences of my students, and my own. All of the ethnographic references were collected in the spring semester of the 2019/2020 study year, and the autumn-winter semester of 2020/202I while lecturing on Gender-specific Socialisation, Family, Women and Gender Studies, and Ethics and Morals in Science at the Faculty of Education, and the Social Sources of Poverty in Youth, and Gender and Violence in the Erasmus programme at the Faculty of Social Work, both at the University of Ljubljana.

The problem of deconstructing institutional hierarchy has been confronted by telling the students about the genealogy of my feminist subjectivation and professional status, and interpreting the basic feminist concepts, some in confrontation with the gender mainstreaming of the European Commission, and the contemporary domineering feminist discourse. The students have given feedback by exhibiting curiosity and the wish that more historical information about feminist movements be presented. In two-way communication, they have enumerated the most important bases of discrimination and oppression, and their awareness of 
everyday discriminatory praxes. Some of them have exhibited the wish to visit or engage in feminist NGOs.

The only obstacle has been ignorance as regards obtaining knowledge on deconstruing the persistence of gender mainstreaming in the interpretation of the gender/sex division. On the other hand, there has been a rewarding recognition of the alienation of women's bodies, whereby the reactions to this recognition were suitably diversified. In all debates, I have cooperated in a just manner, revealing myself in the role of a woman with certain demonstrated and discussed knowledges, skills and experiences, performing a certain role, and not in an a priori authority of a teacher. A teacher position has been humanised by the individualisation procedure and the decomposition of unjust privileges.

The description of the digital flexibility of web lectures and seminars has promoted the invention of less conventional and coded communication and praxis, and the situational introduction of actual socio-political topics not inscribed in the curriculum. One of these outer topics was "gender relations in the anti-Covid-r9 regime". Some already publicly known observations have been thematised, e.g. the accelerated occurrence of domestic gender-based violence, and new burdens of women related to elementary schooling at home (Finley, 2020, para 3). In the class for Gender-specific Socialisation, one student considered the curious occurrence - a non-sensible anti-Covid-Is measure determining the opening hours for the supermarkets. During the first pandemic wave, pregnant women were supposed to go to shop in the same time window in the early hours as retired and handicapped persons, while it was known that older people who got infected experienced severe Covid-Is symptoms (NIJZ - National Institute for Public Health, May 27, 2020).

The university, like other institutions during an autocratisation trend, is experiencing "executive aggrandizement" in that "elected executives weaken checks on executive power one by one, undertaking a series of institutional changes that hamper the power of opposition forces to challenge executive preferences" (Bermeo, 2016, p. I0). Yet, one might realise that the marginalized idea of democratization inspired a new unconventional consolidation of some teachers and students that has occurred in the anti-Covid-rs regime as well as the new comradeship and friendly support amongst the groups of teachers. At least I have had such an experience with some of my feminist colleagues, and there are reports from other countries, too (Dirik, 2020, para 7). These new phenomena of micro-democratisations and solidarity have intentionally or unintentionally been ignored in Slovenia, not thematised in public or professional circles. 
Something complementary to collegial comradeship and the most fulfilling micro-democratisation in teachers happened in a group of students with me as the teacher in the study subject Ethics and Morals in Science. It has not been easy to make the study hours in the heavily-loaded lecture and seminar blocks vivid and interesting. The decision to do auto-ethnographic inquiry into the research "object" which we chose together was crucial. The research on our perception of the "neo-liberalisation" of time and "time management" was multi-layered, the fieldwork had the nature of an experiment, which was organised individually according to subjective goals. When we reported on the results, quite intimate impressions were shared, which connected us well beyond expectations. One student became very emotional because she realised that her time had been spent in the neoliberal mode - her awareness being distracted away from the way the hours of her life had been spent. The emotional tension was released partially in class and later on after the lecture when she phoned me and explained her feelings in a private conversation. She said with a weeping voice that she was depressed, but anyway had the feeling that she had "gained a new insight, which might lead to greater respect for life."

While surveying the impact of Covid-19 and/or virtual teaching and learning on feminist pedagogy as thematised in web publications and journal articles, I have found various perspectives on the topic. The following paragraphs consist of brief excerpts of reports, analyses and guidelines, which I am able to illustrate with my own teaching practice examples.

Virtualisation of study in class is conceived as "the new normal". Experienced intertwinings of so-called private and professional life are reported by the author as tiresome and confusing (Oikawa, 2020, para I). In class, it may be different, the intrusion of domestic scenes, e.g. the sudden appearance of a partner or a child in the room or a dog, attracts new themes. In my case, what happened was a quick hug and kiss on the cheek of a student by her women partner. It reminded me that I was obliged to thematise gay and lesbian couples while discussing heteronormativity, and the illustrative value of the mentioned "intrusion" was adding quality to the lecture. As argued more than a decade ago by Nancy Chick and Holly Hassel, "failing to outline the many ways feminist pedagogy is applicable to online environments will ensure that myths and misconceptions about online teaching flourish and that only the worst versions of online pedagogy persist (Chick \& Hassel, 2009, p. 196). Another reference is derived from the technology and feminism sphere. "They call it 'distance learning,' but it can be intimate, horizontal, distributed, online, in real life learning" (Femtechnet, 2020, p. r). 
The relationship of the digitalised realities and the technical skills of students and teachers constructs students as a skilled entity in opposition to the lack of technological skills in the group of older teachers. As stated by the anthropologists Mariela Nuñez-Janes and Alicia Re Cruz, the online potential as regards adaptability "provides a way to develop and encourage the practice of student centred critical thinking" which foster the principles of "inclusion and legitimizing of students' voices and experiences" (Nuñez-Janes \& Re Cruz, 2007, p. 20). There are two features of the virtual which directly and indirectly construct students as a skilled and knowledgeable subject of study. In my case, the proverbial lack of technological talent in women and especially among older women became the ideal source which I purposefully and truthfully use to show the lack of skills and computer-related technical knowledge. According to the authors cited in the paragraph, such strategies aim "at igniting students' awareness of their value as knowledge producers" (ibid.).

Searching for a web document which would elaborate on a convincing and tested practice of feminist pedagogy, I detected the most structured thematisation of the virtual class in a newly published Sage blog written by Simona Sharoni. She offers a sensitive insight into some of the most important doings of feminist pedagogy: putting the stress on praxis and bravery in times of precarious work, informing the students that the personal is political and the political is personal (Sharoni, 2020, para 2). Her plan to "reimagine the virtual feminist classroom" has the transformative aim to "share power" (ibid., para 4), which I consider the basic and most transformative idea subversive of the patriarchy and the phalocratic organisation of institutions. Among the planned tasks to change the relationship between student and institution, I appreciate the idea of the self-assessment of the students of their work and grades (ibid., para 6). Since it is unclear if she has in mind individual assessment or students' mutual assessing, I am presenting my own praxis. It consists of an assessment of seminar work in a group of students where they mutually give each other feedback regarding the research contents, performance and contact with the public while presenting. These are criteria I have myself suggested and according to which the students decide on their grades with my help as they are hesitant to classify their peers' work in terms of quality.

Under the subtitle "Making a space for students to view the personal as political and the political as personal", Simona Sharoni explains the feminist thesis of second-wave feminism "personal is political" to the students in an illustrative and indirect way. One of the modes is to raise "critical questions that would allow students to identify key social 
and political problems underlying the crisis and the responses". When consulting with students on what to thematise for their seminar research and paper, I have offered them a few thematic options and, as described previously, we together make a decision to do individual research on time and the time pressure characteristic of neoliberal capitalism. In training and experiencing equity, I did the same research topic, although the methods were diverse. The results were generally the same. What is at stake are our lives and not only the quality of the time lived. We are not in a position of controlling our existence in time, the only existence we have. Control is mediated by capital and governmentality.

\section{Conclusion}

While structuring the teaching and learning praxis, one could apply the knowledge of a feminist epistemology origin and the experiences of feminist civil movements. The issue is that there is not one feminist epistemology and hence no dominant discourse. In spite of denying a fixed practice of feminist pedagogy, derived from the one and only referential feminist theoretical background, there is an undeniable resemblance in the diversified construing of feminist pedagogies by practical principles and guidelines. The reason behind this paradox is that feminist pedagogy is inspired by libertarian thought, i.e. deconstructing hegemony and power relations, protecting human rights, integrity and equality accentuated, and questioning the androcentric matrix of thought, with dichotomies being characteristic of its mode. Although most often not explicitly expressed, the aim of feminist pedagogy is to doubt the socio-political and cultural realities, as informed active citizens do. Knowledge as an objective of study is evident, and introducing experience and body is also in line with feminist epistemology and anthropology, philosophy and sociology. The common denominator of feminist pedagogy actually transgresses the sub-disciplinary and disciplinary limits of feminist pedagogy and gender or feminist studies. It is compounded of libertine, democratic ideas and gender awareness, all with defined thought forms integrated into all feminist reflections. Besides the mentioned hegemonic discourse, dichotomies which are reified, and power relations, the intersectional approach to discrimination and exclusion, and the constructions of knowledge and ignorance must be considered, along with a three-level approach to socio- political and socio-cultural realities (analyses on the systemic, structural, and individual levels).

The triangular composition in class where learning and teaching is performed by feminist pedagogy does not imply the question of where the focus should be. What is important is the object transferring to and 
from the instances of the teacher and that of the student or students. It consists of the subject matter and related experiences which cannot be accomplished without interpretation. The experiences reflect mind and emotions and through the latter it is and stays embodied.

The declared transformative aim of feminist pedagogy cannot be reduced to the objective(s) since it refers to society, and the ability of an individual or group to contribute to constructive social change. During the Covid-19 crisis and the measures against it, the virtual class has induced certain changes which may be considered transformative. The "intrusion" of the domestic space may stimulate the teaching and learning process, bring the individualities of students and the teacher closer together, and even make the categorical division public/private transparent in its construed nature. The screen decomposes the hierarchical organisation of the lecturing room, and the adaptive character of the digital programmes enhances students' autonomy by inspiring them to express themselves, while allowing them to exhibit their technical competencies and thus contribute to equality in the positioning of the teacher and the students. Both mentioned conceptualisations of feminist pedagogy - equality, and the two-way transfer of knowledge and skills - seem to be more ideals than realisable goals in the present pedagogic structures. As regards equality, a concept with a similar meaning might be more adequate. While "equality focuses on creating the same starting line for everyone", equity "has the goal of providing everyone with the full range of opportunities and benefits - the same finish line" (IWCA Calgary, 2017). The implied meaning of equity adds to realisation of the two-way transfer of knowledge and skills because it presupposes that the structurally weaker entity that the students entail obtains all the needed attention and resources to reach the position of a fair exchange of knowledge and transferable skills. Simultaneously, teachers should not be embarrassed to inform themselves with the help of the students on a subject they are more knowledgeable of. The intense studying process and reconceptualisation of the previously phalogocentric roles setting call for the renaming of teaching and learning as studying. The teaching function is transformed into moderation in the immediacy of naming. That is, the moderation implies the participation of those who already have the corpus of knowledges and are supposed to be skilled in different activities.

\section{Literature}

Arendt, H. (1973). The Origins of Totalitarianism. Harcourt Brace Jovanovich Publishers. 
R. ŠRIBAR • STUDY IN THE VIRTUAL CLASS: DOINGS OF FEMINIST PEDAGOGY ...

Bermeo, N. (2016). On Democratic Backsliding. Journal of Democracy, 27(1), 5-19.

Cheater, A. (1999). Power in the Postmodern Era. In A. Cheater (Ed.), The Anthropology of Power: Empowerment and Disempowerment in Changing Structures (pp. I-I2). Routledge.

Chick, N., \& Hassel, H. (2009). “Don't Hate Me Because I'm Virtual”: Feminist Pedagogy in the Online Classroom. Feminist Teacher, Ig(3), 195-215. Retrieved November 20, 2020, from http://www.jstor.org/ stable/40546ioo.

Galimberti, G. (2018). Besedo imajo mladi. Dialog z generacijo dejavnega nihilizma [La parola ai giovani. Dialogo con la generazione del nichilismo attivo]. Feltrinelli.

Grensavitch, K. (2019). Thinking with Things: Reimagining the Object Lesson as a Feminist Pedagogical Device in the Humanities Classroom. Theses and Dissertations. 2190. Retrieved November 26, 2020, from https://dc.uwm.edu/etd/2190.

Haraway, D. (1991). Simians, Cyborgs, and Women. The Reinvention of Nature. Routledge.

Hassel, H., \& Nelson, N. (2OI2). A signature feminist pedagogy:

Connection and Transformation in Women's Studies. In N. Chick, A. Haynie \& R. Gurung (Eds.), Exploring more signature pedagogies (pp. I43-155). Stylus.

Lührmann, A., \& Staffan, I. L. (2019). A third wave of autocratization is here: what is new about it? Democratization, 26(7), 1095-1113.

Sharoni, S. (2020). Reimagining a Feminist Virtual Classroom Amidst a Global Pandemic, -- SAGE Perspectives Blog April 8 (sagepub.com). Retrieved November 22, 2020 , from https://perspectivesblog.sagepub.com/blog/ reimagining-a-feminist-virtual-classroom-amidst-a-global-pandemic.

Shrewsbury, C. M. (1993). What Is Feminist Pedagogy? Women's Studies Quarterly, 3-4, 8-16. Retrieved July II, 2020 from https://pdfs.semanticscholar.org/daf2/cci 44aof679b59ea72265ac455c6e66c6f 77 . pdf?_ga=2.

Nuñez-Janes, M., \& Cruz, A. R. (2007). The pedagogy of teaching online graduate courses in the program of applied anthropology. Practicing Anthropology, 29(I), 20-23. Retrieved November 24, 2020 , from http://www.jstor.com/stable/24781694.

Tuana, N., \& Sullivan, S. (2006). Introduction: Feminist Epistemologies of Ignorance. Hypatia, 2I(3), vii-ix. Retrieved November 29, 2020 , from http://www.jstor.org/stable/3810947. 
Vendramin, V. (2009). Od kod prihajajo dejstva? Feminizem in transformacije nekaterih temeljnih epistemoloških pojmov [Where do facts come from? Feminism and transformations of some basic epistemological concepts]. Dialogi, 45(II-I2), 57-67.

\section{Internet Sources}

Dirik, D. (2020). Towards a radical reorganization of life. Resilience, A feminist response to the pandemic. Resilience org. Retrieved September 2, 2020, from https://www.resilience.org/ stories/2020-09-02/a-feminist-response-to-the-pandemic/.

femtechnet.org (2020). Feminist Pedagogy in a Time of Coronavirus Pandemic March 28, 2020. Retrieved July IO, 2020, from https://femtechnet.org/get-involved/self-directed-learners/ key-learning-project.

Finley, E. (2020). Editorial. Sept. 2. Retrieved July II, 2020, from https://www.resilience.org/ stories/2020-09-02/a-feminist-response-to-the-pandemic/.

Lawrence, E. (2016). Feminist Pedagogy, Gender and education association. August 17. Retrieved July I0, 2020, from http://www.genderandeducation.com/issues/feminist-pedagogy/.

Valle-Ruiz, L., et al. (2015). A Guide to Feminist Pedagogy. Vanderbilt Center for Teaching. Retrieved September 20, 2020, from https:// my.vanderbilt.edu/femped/.

NIJZ - National Institute for Public Health (2020). Napotki starejšim [Guidelines for the elderly]. May 27, 2020. Retrieved December, 16, 2020, from https://www.nijz.si/sl/napotki-starejsim. 